\title{
Bifid and secondary superior nasal turbinates
}

\author{
M.C. Rusu' ${ }^{1}$, M. Săndulescu' ${ }^{1}$, C.J. Sava², D. Dincă ${ }^{3}$ \\ 1"Carol Davila" University of Medicine and Pharmacy, Bucharest, Romania \\ 2"Victor Babeș" University of Medicine and Pharmacy, Timișoara, Romania \\ 3"Ovidius" University, Aleea Universității No. 1, Constanța, Romania
}

[Received: 5 March 2018; Accepted: 8 May 2018]

\begin{abstract}
The lateral nasal wall contains the nasal turbinates (conchae) which are used as landmarks during functional endoscopic surgery. Various morphological possibilities of turbinates were reported, such as bifidity of the inferior turbinate and extra middle turbinates, such as the secondary middle turbinate. During a retrospective cone beam computed tomography study of nasal turbinates in a patient we found previously unreported variants of the superior nasal turbinates. These had, bilaterally, ethmoidal and sphenoidal insertions. On the right side we found a bifid superior turbinate and on the left side we found a secondary superior turbinate located beneath the normal/principal one, in the superior nasal meatus. These demonstrate that if a variant morphology is possible for a certain turbinate, it could occur in any nasal turbinate but it has not been yet observed or reported. (Folia Morphol 2019; 78, 1: 199-203)
\end{abstract}

Key words: nasal fossa, nasal concha, bifid turbinate, secondary turbinate, sphenoethmoidal recess

\section{INTRODUCTION}

The lateral nasal wall contains the nasal conchae or turbinates. The inferior one is a separate bone. All the other turbinates are ethmoidal: middle, superior and, occasionally, supreme (Santorini's concha) [3, 9, 15]. Different anatomic variants of nasal turbinates were reported across time. The most common is the middle turbinate pneumatisation (concha bullosa), but all other turbinates were found, although rarely, pneumatized [7].

Bifidity of nasal turbinates is a rare anatomic variation. Bifid middle turbinates [10], as well as inferior bifid turbinates $[1,13,14,17,18,22,23,28]$, were reported.

Extra middle turbinates were previously reported, such as the secondary middle turbinate [4]. This is a bony structure arising from the lateral nasal wall and located lateral to the normal/principal middle turbinate, beneath the basal lamella of middle turbinate, in the middle nasal meatus $[2,26]$.
Paranasal sinuses as well as several regions of the orbit may be accessed through the lateral nasal wall, of which anatomy is dominated by the nasal turbinates [5]. Anatomic variations of turbinates may have impact on the pathology and surgical approaches of paranasal sinuses, orbit or skull base $[5,17,20]$. Such anatomic variations may be recognised on computed tomography sections [1].

To our knowledge there have not been previously reported anatomic variants such as the bifid superior turbinate or the secondary superior turbinate. We found this variation in the case we report here, these two variants being unilateral, on the opposite sides. These were found during a retrospective study of cone beam computed tomography (CBCT) archived files.

\section{MATERIALS AND METHODS}

During a retrospective study of 200 CBCT files, a peculiar anatomic variant was encountered when

Address for correspondence: M.C. Rusu, MD, Dr. Med., Dr. Biol., Dr. Hab., Professor Anatomy, "Carol Davila" University of Medicine and Pharmacy, 8 Eroilor Sanitari Blvd., RO-050474 Bucharest, Romania, e-mail: anatomon@gmail.com

All authors have equally contributed to this paper. 
the archived files of a 54-year-old female patient were explored. The CBCT scan had been indicated for dental procedures, thus the case was not documented endoscopically. The subject were scanned using a CBCT machine - iCat (Imaging Sciences International) with the specific settings detailed previously [19]. We exported the DICOM files for documentation with the Planmeca Romexis Viewer 3.5.0.R software. We evaluated the multiplanar reconstructions (MPRs) in all three dimensions, as well as the three-dimensional volume renderisations (3DVRs) of specified areas using the Soft Tissue filter. Relevant anatomical features were exported as *.tif image files. The patient has given written informed consent for all medical data (including radiographs, CBCT scans and intraoral images) to be used for research and teaching purposes, provided the protection of the identity is maintained.

\section{Anatomic variation}

The anatomical details of the lateral nasal walls were documented on MPRs in all three dimensions, as well as on 3DVRs.

The nasal septum was slightly deviated on the right side, which enlarged the left nasal fossa. On each face of the septum was found a horizontal spur (Fig. 1A). The larger spur was towards the right nasal fossa. Within the postero-superior part of the nasal septum penetrated an anterior (sphenoseptal) recess of the left sphenoidal sinus.

On coronal slices there were identified bilateral agger nasi cells, located anterior and superior to the anterior ends of the middle turbinates. The agger nasi cells were extended posteriorly within the lacrimal bones, superior to the middle turbinates.

The inferior nasal turbinates were morphologically normal, the left one being slightly larger and longer than the opposite one.

The middle turbinates were asymmetrically sized, the left one being obviously larger and longer (Fig. 1). The right middle turbinate was not pneumatized but it presented a paradoxical-like indentation on its medial face at the contact with the right nasal septal spur. In its middle third the left middle turbinate was also paradoxically-like indented by the left spur of the nasal septum (Figs. 1A; 3). Within the lamellar part of the posterior third of middle turbinate was found a small concha bullosa which opened directly in the middle nasal meatus.

On the left side a medially bent uncinate process appeared as accessory middle turbinate (Figs. 1B; 3).
The superior turbinates were bilaterally present, being attached laterally to the ethmoid but also posteriorly to the sphenoidal sinus anterior wall (Fig. 1C, D), thus sphenoethmoidal insertions. The right superior turbinate had a bifid morphology of the free border (Figs. 1A, 1C; 2). On the left side was found a secondary superior turbinate (Figs. 1A, D; 3) which had an ethmoidal insertion different from the superior/ principal one, being located within the superior nasal meatus beneath the respective superior turbinate and superior to the middle turbinate (Figs. 1A; 3 ).

\section{DISCUSSION}

According to Stammberger (1991) [24], quoted in [27], the nasal turbinates develop from a series of ridges in the foetal lateral nasal wall: the maxilloturbinal, the five ethmoturbinals and the nasoturbinal. From the second and the third ethmoturbinal derive, respectively, the permanent middle and superior turbinate $[16,27]$. In these regards, one could not speculate an altered morphogenesis leading to the bifidity of the superior turbinate. However, a secondary superior turbinate occurring between the middle and the superior ones could let one speculate that between the second and third ethmoturbinals a supplemental one was formed and further from it derived the secondary superior turbinate.

On the other hand, the pneumatisation of the superior turbinate is a known anatomic possibility of variation $[6-8,11,12,15,25]$. Therefore, it can be speculated that a largely opened concha bullosa superior could get a bifid appearance. However, the linear aspect of the bifidity we presented in 3DVR is different to a largely opened bullous one and, moreover, it is not inflated from a neighbour pneumatisation. Cobzeanu et al. [7] found pneumatized superior turbinate draining into the sphenoidal sinus and the suprabullar recess.

The superior turbinate was termed by Orlandi et al. [16] "the forgotten turbinate". This although the superior turbinate is well within the field of dissection during posterior ethmoidectomy and sphenoid sinusotomy and is an anatomical landmark of the natural ostium of the sphenoidal sinus. In these regards a bifid morphology or a duplicate of the superior turbinate could impede the specific procedures of functional endoscopic sinus surgery, especially if the anatomic background is poorly documented prior to interventions. Anatomic variations of the superior turbinate also impede the transnasal approaches of the skull base and cranial fossae [15]. 



Figure 1. Cone beam computed tomography multiplanar reconstructions: A. Coronal, through the sphenoethmoidal recesses; B. Coronal, through crista galli; C. Higher axial, through the sphenoethmoidal recesses; $\mathbf{D}$. Lower axial through the sphenoethmoidal recesses. On the right side is identified a bifid superior nasal turbinate (arrow) attached $\left({ }^{*}\right)$ to the respective sphenoidal sinus wall (concha sphenoidalis). On the left side several variations are found: (1) a superior nasal turbinate (double-headed arrow) with ethmoidal and sphenoidal insertion; (2) a secondary superior turbinate (arrowhead) located laterally to the normal/principal one; (3) a moderate paradoxical-like indentation on the convex surface of the middle nasal turbinate (inset) and (4) a secondary middle turbinate (triple-headed arrow); MS — maxillary sinus; SS - sphenoidal sinus.

One approach of the sphenoidal sinus involves resection of the inferior part of the superior turbinate and it was raised the question whether or not this is an olfactory mucosa situs [21]. It was further demonstrated that a loss of olfactory ability could not be determined by such an excision [21].

\section{CONCLUSIONS}

Our findings document previously unknown possibilities of anatomic variation of the superior nasal turbinate, the bifid superior turbinate and the secondary superior turbinate. These demonstrate that if a morphological variant is possible for a certain 



Figure 2. Three-dimensional volume renderizations (filter: Soft Tissue). A. Medial view of right lateral nasal wall, through a breach of the nasal septum; 1 - frontal sinus; 2 - nasal septum (partly); 3 - right middle nasal turbinate; 4 - right inferior turbinate; 5 right superior nasal turbinate, medially viewed; 6 - sphenoidal sinus; B. Oblique inferior view of a cut through the right ethmoidal labyrinth and orbit; 1 - right nasolacrimal canal; 2 - right orbit; 3 - posterior ethmoid air cell; 4 — right temporal fossa; 5 inferior view of the bifid right superior nasal turbinate; 6 - right superior nasal meatus; 7 - greater wing of sphenoid bone; C. Coronal cut, posterior view of nasal turbinates, depicting the bifid right superior turbinate (arrow), the left (principal) superior turbinate (double-headed arrow) and the left secondary superior turbinate (arrowhead).
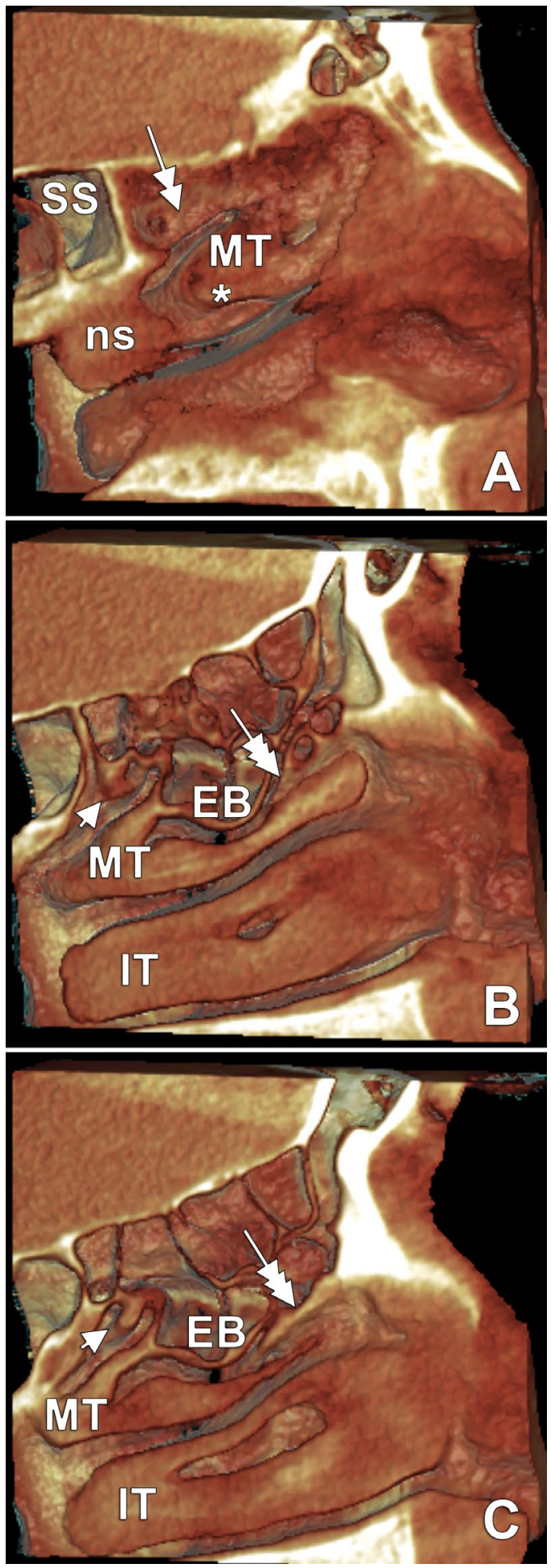

Figure 3. Successive (A-C) three-dimensional volume renderisations of left lateral nasal wall; $\mathbf{A}$. The postero-superior part of nasal septum (ns) is located inferior to the sphenoidal sinus (SS). The left lateral nasal wall attaches the superior (normal/principal) turbinate (double-headed arrow). The middle turbinate (MT) has a minor indentation $\left({ }^{*}\right)$ on the medial side; B, C. The superior turbinate was removed digitally and beneath it a secondary superior turbinate (arrowhead) is found. The MT is sagitally cut and beneath it are observed the ethmoidal bulla (EB) and the medially bent uncinate process which conforms so an accessory middle turbinate (triple-headed arrow); IT — inferior turbinate. 
turbinate, it could be found in any nasal turbinate but perhaps was not observed or reported yet. Specialists should be aware of the possibilities of anatomic variation of turbinates, which may alter drainage pathways or misguide the surgeon.

\section{REFERENCES}

1. Aksungur $E H$, Biçakçi $K$, Inal $M$, et al. $C T$ demonstration of accessory nasal turbinates: secondary middle turbinate and bifid inferior turbinate. Eur J Radiol. 1999; 31(3): 174-176, indexed in Pubmed: 10566516.

2. Al-Qudah MA. Extra middle turbinate lamellas: a suggested new classification. Surg Radiol Anat. 2015; 37(8): 941-945, doi: 10.1007/s00276-015-1435-6, indexed in Pubmed: 25616850.

3. Ariyürek OM, Balkanci F, Aydingöz U, et al. Pneumatised superior turbinate: a common anatomic variation? Surg Radiol Anat. 1996; 18(2): 137-139, indexed in Pubmed: 8782320.

4. Aykut M, Gümüsburun $E$, Müderrïs $S$, et al. The secondary nasal middle concha. Surg Radiol Anat. 1994; 16(3): 307-309, indexed in Pubmed: 7863418.

5. Chastain JB, Sindwani R. Anatomy of the orbit, lacrimal apparatus, and lateral nasal wall. Otolaryngol Clin North Am. 2006; 39(5): 855-864, v, doi: 10.1016/j.otc.2006.07.003, indexed in Pubmed: 16982251.

6. Clerico DM. Pneumatized superior turbinate as a cause of referred migraine headache. Laryngoscope. 1996; 106(7): 874-879, indexed in Pubmed: 8667986.

7. Cobzeanu MD, Bâldea V, Bâldea MC, et al. The anatomo-radiological study of unusual extrasinusal pneumatizations: superior and supreme turbinate, crista galli process, uncinate process. Rom J Morphol Embryol. 2014; 55(3 Suppl): 1099-1104, indexed in Pubmed: 25607391.

8. Fidan V. Panconcha bullosa: new definition in the literature. J Craniofac Surg. 2012; 23(3): e253-e254, doi: 10.1097/ SCS.0b013e31825186b6, indexed in Pubmed: 22627449.

9. Gotlib T, Kuźmińska M, Sokołowski J, et al. The supreme turbinate and the drainage of the posterior ethmoids: a computed tomographic study. Folia Morphol. 2018; 77(1): 110-115, doi: 10.5603/FM.a2017.0067, indexed in Pubmed: 28703849.

10. Kantarci M, Karasen RM, Alper F, et al. Remarkable anatomic variations in paranasal sinus region and their clinical importance. Eur J Radiol. 2004; 50(3): 296-302, doi: 10.1016/j.ejrad.2003.08.012, indexed in Pubmed: 15145491.

11. Kiroglu AF, Cankaya H, Yuca $K$, et al. Isolated turbinitis and pneumatization of the concha inferior in a child. Am J Otolaryngol. 2007; 28(1): 67-68, doi: 10.1016/j.amjoto.2006.06.001, indexed in Pubmed: 17162138.

12. Koo SK, Kim JD, Moon JiS, et al. The incidence of concha bullosa, unusual anatomic variation and its relationship to nasal septal deviation: A retrospective radiologic study. Auris Nasus Larynx. 2017; 44(5): 561-570, doi: 10.1016/j. anl.2017.01.003, indexed in Pubmed: 28173975.

13. Lee JH, Koh SH. A variant form of bifid inferior turbinate. Ear Nose Throat J. 2011; 90(9): E33-E34, indexed in Pubmed: 21938692.
14. Lee SY, Bae KE, Lee HB, et al. Bilateral accessory inferior turbinates and secondary middle turbinates. Jpn J Radiol. 2012; 30(6): 530-532, doi: 10.1007/s11604-012-0082-7, indexed in Pubmed: 22528339.

15. Măru N, Rusu MC, Săndulescu M. Variant anatomy of nasal turbinates: supreme, superior and middle conchae bullosae, paradoxical superior and inferior turbinates, and middle accessory turbinate. Rom J Morphol Embryol. 2015; 56(3): 1223-1226, indexed in Pubmed: 26662164.

16. Orlandi RR, Lanza DC, Bolger WE, et al. The forgotten turbinate: the role of the superior turbinate in endoscopic sinus surgery. Am J Rhinol. 1999; 13(4): 251-259, indexed in Pubmed: 10485010.

17. Ozcan KM, Selcuk A, Ozcan I, et al. Anatomical variations of nasal turbinates. J Craniofac Surg. 2008; 19(6): 16781682, doi: 10.1097/SCS.0b013e318188a29d, indexed in Pubmed: 19098580.

18. Rusu MC, Măru N, Săndulescu M, et al. Rare anatomic variation: true bifid inferior turbinate. Surg Radiol Anat. 2018; 40(2): 217-220, doi: 10.1007/s00276-017-1929-5, indexed in Pubmed: 28948338.

19. Rusu MC, Săndulescu M, Bichir C, et al. Combined anatomical variations: The mylohyoid bridge, retromolar canal and accessory palatine canals branched from the canalis sinuosus. Ann Anat. 2017; 214: 75-79, doi: 10.1016/j. aanat.2017.07.006, indexed in Pubmed: 28823708.

20. Sava CJ, Rusu MC, Săndulescu M, et al. Vertical and sagittal combinations of concha bullosa media and paradoxical middle turbinate. Surg Radiol Anat. 2018; 40(7): 847-853, doi: 10.1007/s00276-018-1998-0, indexed in Pubmed: 29502247.

21. Say P, Leopold D, Cochran G, et al. Resection of the inferior superior turbinate: does it affect olfactory ability or contain olfactory neuronal tissue? Am J Rhinol. 2004; 18(3): 157-160, indexed in Pubmed: 15283489.

22. Selcuk A, Ozcan KM, Ozcan I, et al. Bifid inferior turbinate: a case report. J Laryngol Otol. 2008; 122(6): 647-649, doi: 10.1017/S0022215107009188, indexed in Pubmed: 17592660.

23. Spear SA, Brietzke SE, Winslow C. Bilateral bifid inferior turbinates. Ann Otol Rhinol Laryngol. 2003; 112(2): 195-196, doi: 10.1177/000348940311200217, indexed in Pubmed: 12597297.

24. Stammberger H. Functional endoscopic sinus surgery. BC Decker: Mosby, Philadelphia 1991

25. Toplu Y, Bayindir T, Karatas E, et al. All concha bullosa: an undefined abnormality of the lateral nasal wall. Indian J Otolaryngol Head Neck Surg. 2013; 65(1): 86-88, doi: 10.1007/s12070-012-0592-8, indexed in Pubmed: 24381929.

26. Tubbs RS, Loukas M, Shoja MM. Bergman's comprehensive encyclopedia of human anatomic variation. John Wiley \& Sons, 2016

27. Wang RG, Jiang SC. The embryonic development of the human ethmoid labyrinth from 8-40 weeks. Acta Otolaryngol. 1997; 117(1): 118-122, indexed in Pubmed: 9039492.

28. Yılmaz MS, Güven M, Akidil Ö, et al. Bifid inferior turbinate: a report of two cases. Kulak Burun Bogaz Ihtis Derg. 2014; 24(6): 357-360, doi: 10.5606/kbbihtisas.2014.65624, indexed in Pubmed: 25547752. 